\title{
Comunicação, Música e Territorialidades: repensando a relevância das Cidades Musicais do Rio de Janeiro
}

\author{
Communication, Music and Territoriality: rethinking \\ the relevance of Musical Cities of Rio de Janeiro
}

\begin{abstract}
Micael Herschmann | Universidade Federal do Rio de Janeiro (UFRJ) Doutor em Comunicação pela Universidade Federal do Rio de Janeiro e pesquisador 1 do CNPq. Coordenador do Núcleo de Estudos e Projetos em Comunicação (NEPCOM-UFRJ), coordenador do GT Estudos de Som e Música da COMPÓs e professor do Programa de Pós-Graduação em

Comunicação da UFRJ.

E-mail: micaelmh@globo.com
\end{abstract}

Cíntia Sanmartin Fernandes | Universidade do Estado do Rio de Janeiro (UERJ) Doutora em Sociologia Política pela UFSC, Coordenadora do Programa de Pós-Graduação em Comunicação da UERJ e pesquisadora do CAC-PPGCOM/UERJ.

E-mail: cintia@lagoadaconceicao.com

\begin{abstract}
Resumo
A partir dos estudos de caso das cidades de Rio das Ostras, Conservatória e Rio de Janeiro, vem se avaliando a importância das atividades musicais realizadas ao vivo e nos espaços públicos e privados pelos atores para a ressignificação destas urbes do Estado do Rio de Janeiro. Parte-se do pressuposto de que há uma cultura musical potente nestas localidades, praticada por diversos atores capaz de criar condições não só para a ampliação da sociabilidade, mas também para a ressignificação inovadora das dinâmicas dessas urbes. Um pouco distinto da noção de "cidades musicais" (como modalidade de "cidade criativa" tal como foi formulada pela UNESCO), emprega-se este conceito para designar localidades que possuem "territorialidades sônico-musicais" significativas que vêm promovendo expressivas modificaçóes no imaginário e cotidiano urbano.
\end{abstract}

Palavras-Chave: Comunicação; Cultura; Cidades Criativas; Música.

\begin{abstract}
From the case studies of the cities of Rio das Ostras, Conservatória and Rio de Janeiro, has been evaluating the importance of musical activities live realized in public and private spaces by the actors for the revitalization of these urbes of the State of Rio de Janeiro. This is on the assumption that there is a powerful musical culture in these places, practiced by different actors able to create conditions not only for the expansion of sociability, but also for innovate the dynamics of these cities. Distinct of the notion of "musical cities" (as a form of "creative city" as formulated by UNESCO), is employed this concept to designate locations that have "sonic-musical territoriality" significant that have been promoting significant changes in the imaginary and urban daily life .
\end{abstract}

Keywords: Communication; Culture; Creative Cities; Music 


\section{Introdução}

A partir dos estudos de caso das cidades de Rio das Ostras, Conservatória e Rio de Janeiro, vêm se analisando especialmente a importância das atividades musicais realizadas ao vivo e nos espaços públicos e privados por artistas coletivos e/ou redes sociais, para a ressignificação destas urbes do Estado do Rio de Janeiro, isto é, vem se analisando sua capacidade em converter estes territórios em espaços mais democráticos (com melhores níveis de inclusão e participação social) e com dinâmicas mais "interculturais" (CANCLINI, 2011). Parte-se do pressuposto de que há uma cultura musical potente nestas localidades, praticada por diversos atores (a grande maioria "engajados") que é capaz de criar condiçóes não só para a ampliação da "sociabilidade"1, mas também para a ressignificação inovadora dos espaços dessas cidades (HERSCHMANN e FERNANDES, 2014). Evidentemente, essas urbes possuem também um número consistente de atividades musicais que são programadas para serem realizadas em espaços privados, as quais têm uma função importante na construção de "territorialidades" (HAESBERT, 2010) e dinâmicas de trocas que gravitam em torno da música (infelizmente nem sempre estes espaços são capazes de proporcionar o intercâmbio mais consistente entre variados segmentos sociais). Mais do que isso: essas cidades têm sido capazes de abrigar - especialmente em função da articulação dos atores locais - "cenas musicais" (STRAW, 2006) significativas no seu território².

A hipótese que norteia este artigo é a de que existiriam cidades musicais pelo Brasil e pelo mundo (evidentemente, que com suas respectivas e relevantes singularidades), tais como as três cidades que estão sendo pesquisadas. Um pouco distinto da noção de cidades musicais (como modalidade de "cidade criativa"3 ), tal como foi formulada pela $\mathrm{UNESCO}^{4}$, emprega-se aqui este conceito para designar localidades que possuem "territorialidades sônico-musicais" significativas que, pela ação ao longo do tempo, promovem expressivas modificaçóes no imaginário e cotidiano urbano (BENNETT et al., 2014; WYNN, 2015).

Ou seja, essas "territorialidades sônico-musicais" - pela recorrência da sua presença, intensidade dos afetos suscitados (que promovem enorme mobilização), pluralidade e pela sua multiplicação em diversas áreas - acabam produzindo efeitos significativos em partes da cidade ou na urbe como um todo. Vale ressaltar que a tendência da UNESCO é considerar as cidades criativas (e musicais) como centros de excelência tendencialmente institucionalizados. Isso vale também para boa parte da literatura especializada neste conjunto de temáticas (BRADFORD, 2004; FLORIDA, 2002 E 2005; HARTLEY, 2005; HOWKINS, 2001 e 2009; LANDRY, 2000, 2006 E 2009; LANDRY e BIANCHINI, 1994; LERNER, 2009; REIS, 2008, 2010 e 2012; REIS e KAGEYAMA, 2009; SCOTT, 2006; THROSBY, 2001). Nesse sentido, para o arquiteto Charles Landry, que supostamente cunhou o conceito (um tanto impreciso e polêmico) de "cidades criativas" em 1995 (com Franco Bianchini), seria preciso criar um ambiente estruturado que propicie condiçóes para aflorar não só a imaginação, mas também a participação pública. 
potencial em qualquer lugar do que pensariamos à primeira vista (...). Parte-se do pressuposto de que devem ser criadas condiçóes estruturais para que as pessoas pensem, planejem e ajam com imaginação para aproveitar oportunidades ou resolver problemas aparentemente intratáveis (...). Isso significa que as cidades grandes e pequenas podem ser criativas. A hipótese é a de que as pessoas comuns podem fazer coisas extraordinárias acontecerem se tiverem oportunidades (LANDRY, 2009, p. 3 e 4).

Portanto, ainda que essas urbes possam ter suas atividades musicais institucionalizadas (mais ou menos apoiadas pelo Estado e por empresas privadas), considera-se aqui relevante contemplar também as inúmeras iniciativas espontâneas (marcadas pela informalidade) desenvolvidas pelos atores em um território. Aliás, o que em geral se observa é que os atores parecem mais engajados quando identificam que há espontaneidade nas iniciativas (identificada por eles com a noção de "autenticidade" e fidelidade aos interesses da rede da qual fazem parte), quando se sentem efetivamente protagonistas das atividades e que são capazes de construir "heterotopias" que possuem vitalidade. Parte-se da convicção que os atores acreditam que é possível construir um "modo de ser" e de "estar-junto" (MAFFESOLI, 2009) "alternativo", o que Harvey denominou de "utopismo espaço-temporal" ou "utopismo dialético" (HARVEY, 2009). ${ }^{7}$

Assim, em conversas formais e informais, vários atores quase sempre mencionam uma grande desconfiança em relação aos processos de institucionalização envolvendo os setores criativos. Portanto, argumenta-se que esses processos - na área da música - são muito mais complexos do que aparentam: institucionalizar e apoiar com recursos não tenderia necessariamente a garantir a presença de atores mobilizados e atuantes em uma localidade. Ainda que os preceitos que orientam este trabalho coincidam com alguns dos postulados da UNESCO no que tange a esta temática, parte-se do pressuposto de que são os atores (no cotidiano) é que efetivamente constroem - com ou sem apoio institucional - uma "cidade musical".

Vale ressaltar ainda que há uma literatura - especialmente anglo-saxã (BENNETT et al., 2014; WYNN, 2015) - que considera que o momento de organização e realização do festival, por ser um acontecimento que agrega os atores de diferentes segmentos sociais (que produz sinergias entre grupos mais ou menos organizados, empresários e Estado), é que poderia alavancar não só o desenvolvimento local (a cultura emergiria na atualidade como um "recurso"8 ), mas também uma "sociabilidade cosmopolita" (e até instaurar relaçôes mais “interculturais" em um território). Ora, sem discordar inteiramente desta literatura, o que a investigação em curso vem demonstrando é que isso eventualmente acontece em algumas cidades, mas há processos e desdobramentos que vão em outras direçóes e exigem uma reflexáo mais crítica e rigorosa.

Analisando de maneira crítica a maioria das intervençôes que são orquestradas pelo poder público e pelo capital (local e transnacional) - com mais ou menos apoio dos atores - no mundo contemporâneo globalizado, é possível atestar que inúmeras vezes os políticos e autoridades afirmam junto a diferentes setores das sociedades que estão construindo uma cidade criativa, mas frequentemente o que se assiste é a implementação de um conjunto de 
"estratégias de city marketing" (REIS, 2012). Se analisamos o planejamento e as intervençóes conduzidas nestas urbes constatamos que os processos são exógenos e operam a partir de uma lógica mimética (copia-se modelos de metrópoles supostamente exitosas) e ostentatória (valoriza-se náo só tudo que possa ser excessivamente espetacularizar ou apto a produzir sinergias com o branding territorial, mas também as mega obras e a construção de grandes equipamentos urbanos), capazes de atrair turistas e investimentos que visam em última instância enriquecer investidores e grupos políticos específicos (os objetivos são financeiros e de crescimento da máquina urbana) ${ }^{\mathbf{1 0}}$.

Portanto, por um lado, há que reconhecer também que existem processos de "festivalização de uma cidade" (BENNETT et al., 2014) os quais redundam em projetos excludentes (em geral voltados para o turismo e para a elite econômica) - de gentrificação e alijamento da população mais pobre que vê negado o seu "direito a cidade" -, por outro lado, muitas vezes as localidades se constituíram ao longo de períodos significativos de tempo (no cotidiano) como cidades musicais através de iniciativas envolvendo os músicos, redes de fâs e empreendedores, sem passar direta ou indiretamente pelo apoio ou intervençóes levadas a cabo pelo poder público.

\section{Revalorização da música ao vivo}

É preciso sublinhar que quando nos referimos às "cidades musicais" estamos colocando em relevo especialmente atividades que gravitam em torno da música ao vivo, que hoje - pelos recentes dados divulgados pela IFPI (2016) - representam aproximadamente 70\% dos ganhos da indústria da música. Sem menosprezar a relevância da venda em suporte físicos e digitais de fonogramas e o intenso intercâmbio de conteúdo, os quais são muito significativos especialmente para a promoção do trabalho dos artistas, é preciso reconhecer a importância hoje dos concertos ao vivo e festivais para inúmeros atores: para os músicos, para a geração de milhares de empregos diretos e indiretos e para o dinamismo das cidades (ou pelo menos para o desenvolvimento de estratégias de branding ou marketing territorial).

Poder-se-ia afirmar que há mais de quinze anos se assiste a um processo de transição da indústria da música no mundo. Essas transformaçôes na indústria da música estão relacionadas, em grande medida, à emergência de uma cultura digital. Evidentemente, não se trata de uma ruptura completa em relação ao mercado da música do século XX, mas o largo emprego dos processos comunicacionais e das novas tecnologias vêm afetando de forma significativa este setor da atividade cultural e econômica. Vale recordar que a indústria da música gravada se desenvolveu tanto no século passado que, em determinado momento, passou a usar a música ao vivo como forma de promover a música gravada, invertendo a situação de centralidade da música ao vivo que existia (HERSCHMANN, 2010). Ainda que os dados de vendas digitais através de plataformas de streaming venham tendo resultados um pouco mais animadores nos últimos dois anos, sem dúvida é possível afirmar que hoje estes papéis se inverteram. 
Portanto, é preciso enfatizar que o debate sobre as cidades musicais está centrado na música ao vivo, que vem comprovando neste período de transiçáo ser um mercado capaz de mobilizar os consumidores sem dúvida pela sua capacidade movente (HERSCHMANN e FERNANDES, 2013). Alguns autores sugerem que o sucesso da música ao vivo está relacionado a emergência de uma cultura do entretenimento que se pauta pela oferta de uma experiência coletiva/ social - de escapismo, fruição e/ou imersão - que é valorizada pelos atores. Em outras palavras, esses autores argumentam que assistiríamos à valorização expressiva de um setor "pós-serviço", de um mercado ou de uma "economia da experiência” (PINE e GILMORE, 2001). A subida nos últimos anos dos valores das entradas dos concertos no mundo globalizado, por exemplo, seria um claro indicio disso (HERSCHMANN, 2010).

\section{Cidades Musicais do Estado do Rio de Janeiro}

Apresenta-se a seguir algumas informaçôes sobre o contexto no qual vem sendo desenvolvido este trabalho, tendo como finalidade fornecer alguns detalhes dos estudos de caso que vêm sendo estudados. Apesar do Estado do Rio de Janeiro ser um celeiro da produção musical e audiovisual do país, durante muito tempo o poder público apostou nos royalties do petróleo como a coluna vertebral de crescimento econômico e social da regiáo. ${ }^{11}$ Nos últimos anos, o debate sobre a indústria e as cidades criativas ganhou espaço junto a tecnocracia local. Infelizmente, no que se refere a principal metrópole da regiáo, a aposta por enquanto na cidade do Rio é na realização de megaeventos (como a Copa do Mundo e as Olimpíada, além de megafestivais como, por exemplo, o Rock in Rio) e na realização de algumas intervençóes urbanas que vêm excluindo boa parte da população e aprofundando as diferenças sociais. Denúncias de desrespeito aos direitos civis envolvendo desapropriaçôes, corrupção envolvendo empreiteiras e favorecimentos de fortes grupos econômicos nacionais e internacionais tomaram conta do noticiário e das mídias sociais, desacreditando de forma contundente a tese de que estes investimentos que estão sendo feitos nesta cidade visam o bem-estar comum e deixarão, portanto, legados sociais relevantes (HERSCHMANN e FERNANDES, 2014).

A despeito de certo descaso do poder público em relação a música à exceção da aprovação da democratizadora e, ao mesmo tempo, polêmica Lei Municipal do Artista de Rua (promulgada em 2012 por muita pressão dos movimentos sociais deflagrados pelos artistas locais) -, as atividades musicais realizadas nos espaços privados e públicos vêm também desempenhando um relevante e estratégico papel na ressignificação do Estado do Rio de Janeiro, tal como pode ser constatado, por exemplo, pelo crescente e estrondoso êxito de algumas áreas do Centro da capital que hoje abrigam Polos Históricos, Gastronômicos e Culturais estratégicos do Rio. São casos exemplares, de sucesso socioeconômico (vem dinamizando expressivamente o comércio local), os quais atraem grande visitação e hoje reúnem um extenso número de atividades culturais e turísticas que são estratégicos para a cidade (HERSCHMANN, 2007 e 2010) ${ }^{\mathbf{1 2}}$. 
O estudo de caso mais conhecido nesta região do Centro da cidade é o bairro da Lapa que, a partir do final dos anos de 1990, passou a se constituir em uma das principais vitrines para a música ao vivo do país. Estruturado pelos atores - artistas, proprietários de casas de espetáculo e produtores culturais - e com pouca participação do Estado, vale ressaltar que a Lapa se organizou em torno de circuitos musicais de música mais tradicionais como o samba e choro (evidentemente, nos dias atuais, é mais diversificada a sua programação) que passaram a atrair em média 400 mil pessoas por mês (HERSCHMANN, 2007).

Posteriormente, na década passada com a implementação de algumas políticas públicas locais houve um processo de gentrificação deste território e expulsou-se boa parte do público que possui menor poder aquisitivo. ${ }^{13}$ Mesmo com este processo de exclusão e direcionamento da localidade para um público turístico e da elite econômica, a Lapa segue sendo um êxito: para que se tenha uma ideia, na década passada, dos 20 milhóes de dólares que foram gerados ao mês na economia da cultura da Lapa, calcula-se que cerca de $1 / 3$ são provenientes das atividades relacionadas aos concertos ao vivo locais (HERSCHMANN, 2007).

Ao mesmo tempo, vale salientar que cidades pequenas e turísticas como Conservatória e Rio das Ostras que vêm experimentando há muitos anos ciclos de crescimento socioeconômico, tem obtido estes resultados por conta das atividades musicais realizadas ali (que gravitam em torno de "gêneros musicais"14 importantes no contexto nacional), isto é, essas são em alguma medida responsáveis pelos patamares de desenvolvimento alcançados ${ }^{15}$ nestas pequenas urbes. Em outras palavras, nas cidades investigadas vêm se constatando a importância dessas atividades para a ressignificaçáo destas urbes do Estado do Rio de Janeiro. Isto é, considera-se estes estudos de caso especialmente relevantes, pois sugerem alguns dos principais desafios que se colocam na atualidade às cidades musicais.

O caso do distrito de Conservatória é muito interessante, pois vem alcançando significativo êxito há mais de 70 anos. Na realidade, esse sucesso é impulsionado por um ativismo de músicos amadores da terceira idade que todos os finais de semana se dirigem para este local para cantar seresta de forma nômade, pelas ruas desta pequeno e charmoso vilarejo. Esses ativistas (a grande maioria engajados) se dedicam a esta atividade sem visar nenhum tipo de ganho econômico, apesar desta iniciativa gerar inúmeros benefícios para donos de hotéis, bares e restaurantes. Analisando a trajetória da localidade é possível constatar que foi o movimento seresteiro que contribuiu expressivamente para a construção do "perfil" atual da cidade.

A partir da década de 1960, a realização mais frequente das serestas e serenatas e a criação do Museu da Seresta e da Serenata (como tradicional ponto de encontro do movimento) são apontados pelos atores como marcos históricos do fortalecimento deste movimento musical. Cabe ressaltar ainda que vários dos entrevistados assinalam ainda que foi também neste período que a memória seresteira ganhou as ruas de Conservatória, com o projeto "Conservatória, em toda casa uma cançáo", quando em todas as casas da cidade passaram a ser instaladas placas alusivas às músicas cantadas nas serestas e serenatas ${ }^{\mathbf{1 6}}$. O fato é que cada vez mais este vilarejo ganhou ares de 
uma espécie rara de "parque temático" (com as casas e negócios ganhando nomes de músicas do repertório seresteiro, isto é, no centro histórico o visitante encontra, por exemplo, a loja de livros Canto Lírico, a padaria Lua Branca e Restaurante Dó-Ré-Mi e assim por diante), marcado pelo afeto e amadorismo do movimento seresteiro, capaz de atrair um grande número de fấs desses gêneros musicais (HERSCHMANN e FERNANDES, 2014).

Evidentemente, o sucesso de Conservatória nas últimas décadas acabou atraindo o interesse de técnicos e consultores do poder público, que identificaram nesta localidade um caso em que a "economia da cultura" foi capaz de alavancar Desenvolvimento Local. Vários tecnocratas passaram a considerar Conservatória como mais uma experiência positiva de associativismo entre atores e empreendedores locais: similar à ocorrida em outras cidades do mundo e fartamente descrita na literatura que analisa a trajetória de clusters, arranjos produtivos locais e distritos industriais.

Assim, tendo em vista seguidas avaliaçôes feitas por consultores de diversas instituiçóes de fomento, a localidade de Conservatória passou a ser considerada, no início do século XXI, como primeiro Arranjo Produtivo Local de Entretenimento do Brasil. Desse modo, foi estabelecida uma Coordenação Local do "Projeto do APL" - com o apoio especialmente do Governo do Estado do Rio - e passaram a ser desenvolvidas uma série de açóes como, por exemplo, a construção de uma subestação de energia elétrica, abertura de estradas de acesso e a criação e diversificaçáo de um calendário de eventos anual, que tiveram como objetivo incrementar o desenvolvimento na região. Apesar de várias políticas públicas equivocadas que vêm sendo implementada na regiáo - que propóem, entre outras coisas, profissionalizar a atividade musical dos seresteiros - Conservatória segue muito ativa e continua sendo, especialmente para os frequentadores, a "capital da seresta do país" (HERSCHMANN e FERNANDES, 2014).

O caso de Rio das Ostras é talvez o que mais se aproxima do que ocorre de forma recorrente na Europa e que é analisado fartamente pela literatura que trata da "festivalização da cultura" (BENNETT et al., 2014) e que sublinha a importância desses eventos para o desenvolvimento dos territórios. Na realidade, este é um caso de uma cidade balneária pouco conhecida que conseguiu ganhar visibilidade e alavancar o seu desenvolvimento (OLIVEIRA, 2014) - especialmente no setor turístico - a partir da implantaçáo de um festival de jazz e blues. Apesar do expressivo êxito alcançado (desde a sua criação em 2002), este evento anual tem pouco apoio por parte do poder público local, isto é, sustenta-se pela iniciativa de algumas poucas lideranças, produtores culturais e empresários locais. Curiosamente, um pouco distinto do que objetivavam seus organizadores ao planificar a realização deste festival (que tem destaque no calendário e circuito nacional associados a esses gêneros musicais): mais do que apenas dinamizar a cadeia do turismo, estes concertos passaram a atrair e mobilizar significativamente os moradores da cidade (inclusive aqueles oriundos das camadas menos privilegiadas da população), em função do caráter público e gratuito desses eventos. ${ }^{17}$ 
E, finalmente, temos o caso da metrópole do Rio de Janeiro que, evidentemente, é de significativa complexidade e envolve atividades realizadas nos espaços públicos e privados; de forma paga e gratuita; através de concertos, festas e festivais; com ou sem apoio do Estado.

Não há aqui condiçôes aqui de traçar um painel de análise detalhado, mas analisa-se brevemente um estudo de caso, bastante ilustrativo (em uma localidade, a qual o poder público vem investindo significativamente), de situaçóes que vêm ocorrendo de forma recorrente no cotidiano desta cidade nos últimos anos ${ }^{18}$. A recente reforma da zona portuária (inspirada nas reformas feitas em Barcelona, na época da Olimpíada organizada nesta cidade catalã) e o investimento em mega equipamentos culturais, especialmente em museus (ressalta-se que foram construídos dois recentemente no Rio) e a aposta no potencial transformador e movente dos mega eventos - inclusive os grandes festivais de música e de artes (que passaram a ser realizados nos antigos armazéns de carga da área do porto) - não vem garantindo até o momento a tão esperada ressignificaçáo desta regiáo do Centro do Rio de Janeiro (HERSCHMANN e FERNANDES, 2014).

$\mathrm{Na}$ realidade, acompanhando as dinâmicas de "reagregação social" dos atores (LATOUR, 2012) - com suas "táticas" e "artes de fazer" (DE CERTEAU, 1995) - constata-se que a pièce de resistance que vem garantindo um dinamismo na regiáo seriam muito mais os pequenos eventos musicais (microeventos) organizados por músicos e suas redes de fãs que vem ofertando quase que diariamente, de forma gratuita nas ruas, praças e becos, principalmente nos arredores do Morro da Conceição (mais especificamente na localidade e vizinhanças da Pedra do Sal), os quais vêm atraindo regularmente milhares de pessoas de todos os segmentos sociais.

Estes eventos não têm visibilidade na mídia tradicional, mas são amplamente conhecidos pelo público, através das redes sociais. São esses pequenos concertos gratuitos e regulares que vêm atraindo jovens e artistas para esta região e que vem dinamizando este território. Assim, assiste-se na cidade do Rio de Janeiro a aposta em um projeto de construção de uma cidade globalizada com um branding territorial fortalecido, a qual não leva em consideração as dinâmicas culturais presentes - os ecossistemas socioculturais existentes, de pouca visibilidade e/ou pouco institucionalizados - na metrópole (HERSCHMANN e FERNANDES, 2014).

É preciso sublinhar que nem sempre investir em mega obras, traduz-se no final do processo em resultados significativos, os quais são revertidos para o bem coletivo ou comum. Temos um museu construído pelo renomado arquiteto espanhol Santiago Calatrava, mas, ao mesmo tempo, destruímos nesta localidade parte significativa da memória afro-brasileira local (havia na regiáo sítios arqueológicos relevantes da chamada "Pequena África"19). Infelizmente, o caso da metrópole do Rio de Janeiro indica que há com frequência um distanciamento e/ ou tensóes entre as "políticas do comum"20 (HARDT e NEGRI, 2009) e as políticas públicas (mesmo em relação à algumas, supostamente mais progressistas) que, de modo geral, vêm sendo implementadas no país. 


\section{Considerações finais}

Diante do exposto poder-se-ia afirmar que persiste uma carência de políticas mais democráticas capazes de dinamizar o Estado do Rio de Janeiro, o qual possui uma cultura musical (inclusive voltada para os espaços públicos) que tem vitalidade e que promove uma dinâmica de aproximação entre diferentes segmentos sociais (basta ver o que representa do ponto de vista socioeconômico o carnaval, especialmente o de rua, para a região ${ }^{21}$ ).

O fato é que o que vem alicerçando a vitalidade desta localidade musical ${ }^{22}$ é basicamente o empreendedorismo, a criatividade e/ou engajamento dos atores (HERSCHMANN e FERNANDES, 2014). ${ }^{23}$ Como se pode constatar aqui, estudar as urbes musicais do Rio de Janeiro e/ou do país significa se debruçar sobre um conjunto de temáticas de grande relevância e atualidade, as quais estáo tendo implicaçóes diretas e indiretas sobre aspectos socioculturais, políticos e econômicos desses territórios.

\section{Referências bibliográficas}

BECK. Ulrich. Qu' est-ce le cosmopolitisme? Bris: Édition Aubier, 2006.

BENNETT, Andy et al. (eds.) Festivalization of Culture. Nova York: Routledge, 2014.

BRADFORD, Neil. Creative Cities structured policy dialogue backgrounder. Otawwa: Canadian Policy Research Networks, 2004.

CANCLINI, Néstor G. Diferentes, desiguais e desconectados. Rio de Janeiro: Ed. UFRJ, 2015. . (org.) Conflictos interculturales. Barcelona: Gedisa, 2011.

CONNOR, Steven. Dumbstruck: a Cultural History of Ventriloquism. Oxford: Oxford University Press, 2000.

DE CERTEAU, Michel. A invenção do cotidiano. Petrópolis: Vozes, 1995.

DE NORA, Tia. Music and Everyday Life. Cambridge: Cambridge University Press, 2000.

FERNANDES, Cíntia S. Música e Sociabilidade: o samba e choro nas ruas-galerias do Centro do Rio de Janeiro. In: HERSCHMANN, Micael (org.) Nas bordas e fora do mainstream musical. São Paulo: Estação das Letras e das Cores, 2011.

FERNANDES, Cíntia S., TROTTA, Felipe.; HERSCHMANN, Micael. Não pode tocar aqui!? In: E-Compós. Brasília: COMPÓS, vol. 18, n. 2, 2015.

FLORIDA, Richard. The rise of the creative class. Nova York: Basic Books, 2002.

. Cities and the creative class. Nova York: Routledge, 2005.

FREIRE FILHO, João. Reinvençōes da resistência juvenil: os estudos culturais e as micropoliticas do cotidiano. Rio de Janeiro: Mauad X, 2007. 
FOUCAULT, Michel. O corpo utópico, as heterotopias. São Paulo, N-1 Edições, 2013.

HAESBAERT, Rogério. O mito da desterritorialização: do fim dos territórios à multiterritorialidade. Rio de Janeiro: Bertrand Brasil, 2010.

HARDT, Michael; NEGRI, Antonio. Commonwealth. Massachusetts: Harvard University Press, 2009.

___________. Império. Rio de Janeiro: Record, 2000.

HARTLEY, John (ed.) Creative Industries. Oxford: Blackwell Publishing, 2005.

HARVEY, David. Espaços de Esperança. São Paulo: Ediçóes Loyola, 2013.

HERSCHMANN, Micael. Induistria da música em transição. São Paulo: Ed. Estação das Letras e das Cores, 2010.

. Lapa, cidade da música. Rio de Janeiro: Mauad X, 2007.

. Cenas, Circuitos e Territorialidades Sônico-Musicais. JANOTTI

JUNIOR, Jeder; SÁ, Simone P. (orgs.). Cenas Musicais. Guararema: Anadarco, 2013.

HERSCHMANN, Micael; FERNANDES, Cíntia S. Música nas ruas do Rio de Janeiro. São Paulo: Ed. Intercom, 2014.

; - Potencialidade movente do entretenimento, da música e espacialidade no Rio de Janeiro. RIBEIRO, Ana P.; FREIRE Fo., João; HERSCHMANN, Micael. Entretenimento, Felicidade e Memória: forças moventes do contemporâneo. Guararema: Anadarco, 2013.

.;_______. Bem-vindo ao Rio de Janeiro depouca visibilidade!In: Anais do XXXVIII Congresso da INTERCOM. São Paulo: INTERCOM, 2015.

HOWKINS, John. The creativy economy. Londres: Penguin Books, 2001. . Creative ecology. St. Lucia: UQP, 2009.

IFPI. Global Recording Industry in numbers - 2015. Londres: IFPI Market Publication, 2016.

KITTLER, F. Gramophone, Film, Typewrither. Stanford: Stanford University Press, 1999.

LABELLE, Brandon. Acoustic Territories/Sound Culture/ Everyday Life. Nova York: Continuum, 2010.

LANDRY, Charles. The art of city-making. Londres: Easthscan, 2006. The creative city. Londres: Easthscan, 2000. Prefácio. REIS, Ana C.; KAGEYAMA, Peter. (orgs.). Creative cities perspectives. Sáo Paulo: Garimpo de Soluçóes, 2009. 
LANDRY, Charles; BIANCHINI, Franco. The Creative City. Londres: Comedia, 1994.

LATOUR, Bruno. Reagregando o social. Salvador: EDUFBA, 2012.

LÉFÈBVRE, Henri. A Revolução Urbana. Belo Horizonte: ED. UFMG, 2004. . O direito à cidade. São Paulo: Centauro, 2015.

LERNER, Jaime. Every city can be a creative city. REIS, Ana C.; KAGEYAMA, Peter. (orgs.). Creative cities perspectives. São Paulo: Garimpo de Soluçóes e Creative Cities Productions, 2009.

MAFFESOLI, Michel. O mistério da conjunção. Porto Alegre: Sulina, 2009.

NEGUS, Keith. Géneros musicales y la cultura de las multinacionales. Barcelona: Paidós, 2005.

OLIVEIRA, Indira Rodrigues de. Comunicação e Música: os agenciamentos do Jazz \& Blues da cidade de Rio das Ostras. In: IV COMUSICA, Rio de Janeiro. Anais do IV COMUSICA. Rio de Janeiro: UERJ, 2014.

PINE, B. Joseph; GILMORE, James. O espetáculo dos negócios. Rio de Janeiro: Campus, 2001.

PRESTES FILHO, Luís C. et al. (Coords.). Cadeia produtiva da economia da música. Rio de Janeiro: Instituto Gênesis/ PUC-RJ, 2004.

REIS, Ana Carla. Cidades Criativas. São Paulo: SESI-SP, 2012. . Economia criativa e desenvolvimento. São Paulo: Itaucultural, 2008. . Cidades criativas, soluçôes inventivas. São Paulo: Garimpo de Soluçóes, 2010.

REIS, Ana C.; KAGEYAMA, Peter. (orgs.). Creative cities perspectives. São Paulo: Garimpo de Soluçóes e Creative Cities Productions, 2009.

SCOTT, Allen J. Creativescities: conceptualissuesandapoliciyquestions. Londres: s.ed., 2006 (disponível em: <escholarship.org/uc/item/77m9g2g6>. Acesso em: 12 de junho de 2016).

STRAW, Will. Scenes and Sensibilities. E-Compós. Brasília: COMPÓS, n. 6, 2006.

THROSBY, David. Economía y cultura. Madrid: Cambridge University Press, 2001.

WYNN, Jonathan. Music/City. Chicago: University of Chicago Press, 2015.

YÚDICE, George. A conveniência da cultura. Belo Horizonte: Ed. UFMG, 2005.

\section{Notas}

1. Evidentemente, como muitos estudos têm observado, tais encontros podem gerar não só processos de agregação, mas também dinâmicas que incitam rivalidades e tensões sociais. Para mais detalhes sobre a relevância da sociabilidade na sociedade contemporânea, cf. CANCLINI, 2015; MAFFESOLI, 2009. 
2. A noção de cena é utilizada aqui como uma alternativa ao conceito de "subcultura", a qual não se adéqua bem às "dinâmicas sociais que estão relacionadas às práticas culturais contemporâneas", à medida que estas tendem a ser mutáveis, fugazes, fluidas e, muitas vezes, arbitrárias (Freire Filho, 2007). Para Straw (2006), a cena sugere mais do que a fluidez agitada da sociabilidade urbana: compele-nos a examinar o papel das afinidades e interconexóes que marcam e regularizam os itinerários espaciais de pessoas, coisas e ideias, através do tempo. Poderia se listar algumas das condiçóes que facilitam o desenvolvimento de uma cena musical qualquer (que foram levados em conta aqui): a) presença de programas de rádio, blogosfera e redes sociais dando visibilidade às iniciativas; b) regularidade na realização de concertos na rua e em casas de espetáculos; c) espaço significativo e frequente na mídia tradicional; d) presença de uma produção fonográfica local regular; e) e a estruturação de circuitos de festivais e eventos (HERSCHMANN, 2013).

3. Os conceitos de "indústrias criativas", "economia criativas" e "nação criativa" do qual derivou o conceito de "cidades criativas" (a maioria desses cunhados na primeira metade dos anos de 1990) incluem dinâmicas de produção, circulação e consumo de bens criativos e culturais abrangendo de forma difusa áreas como arquitetura, artes, artesanato, antiguidades, audiovisual, design, edição, videogames, softwares, moda, música, publicidade, televisão, teatro e rádio. De modo geral, os setores criativos constituem-se em um conjunto de setores absolutamente heterogêneos que adquirem, em geral, grande visibilidade graças a força e onipresença turismo globalizado e a força e da lógica do entretenimento no cotidiano (mais detalhes, conferir: HARTLEY, 2005; REIS, 2012). Segundo a UNESCO, as "cidades criativas" reuniriam setores das indústrias criativas potentes no seu território (mais informaçôes ver: http://en.unesco.org/creative-cities/home). Sobre a polissemia de significados atribuídas ao conceito de "cidades criativas" ver Reis, 2012.

4. Em 2004 a UNESCO criou Rede de Cidades Criativas (UCCN) para promover a cooperação com e entre as cidades que identificaram a criatividade como um fator estratégico para o desenvolvimento urbano sustentável. Há mais de uma centena de cidades que atualmente compõem essa rede da UNESCO e que têm supostamente um objetivo comum: colocar a criatividade e as indústrias culturais no coração de seus planos de desenvolvimento no âmbito local e cooperar ativamente no âmbito internacional. Essa rede abrange sete campos criativos: artesanato \& arte popular, media art, cinema, design, gastronomia, literatura e música. Instituiçóes públicas importantes de uma localidade - que é centro de excelência de algumas dessas atividades criativas - podem apresentar a candidatura de uma cidade (ou pequeno país) a UNESCO. No caso das cidades musicais, existiam mais de uma dezena delas no mundo até 2016 (mais detalhes, conferir: http://en.unesco.org/creativecities/home).

5. Com a noção "territorialidades sônico-musicais" busca-se valorizar a importância da música e das inúmeras sonoridades presentes no cotidiano das cidades para os processos de reterritorializaçáo que vêm sendo realizados pelos atores nesses espaços. Muitas vezes a decisão da área que será ocupada com música leva em conta não só a circulação dos atores, mas também o fluxo e a intensidade dos fluxos sônicos do local (Herschmann e Fernandes, 2014). Essas territorialidades - mais ou menos temporárias -, pela sua regularidade, geram uma série de benefícios locais diretos e indiretos para o território (permitindo até o incremento das atividades socioeconômicas locais). Aliás, como sugerem alguns autores de Sound Studies 
(LABELLE, 2010; KITTLER, 1999; CONNOR, 2000, DE NORA, 2000), essas territorialidades são relevantes porque afetam o ritmo, o imaginário e os corpos no dia a dia, reconfigurando de alguma maneira os territórios. Essas territorialidades, portanto, construiriam novas cartografias sônicas ou acústicas da cidade.

6. Como inúmeros autores das ciências sociais já assinalaram, não se trata aqui de apostar na capacidade dos atores em (re)construir uma utopia ou "utopismo espacial tradicional" (HARVEY, 2009). Portanto, emprega-se aqui a noção de heterotopias náo exatamente no sentido Foucaultiano - como conjunto de práticas, na maioria das vezes, a serviço do "biopoder" (FOUCAULT, 2013) - e mais no sentido utilizado por Léfébvre (2004 e 2015) como iniciativas potentes, que poderiam conduzir a dinâmicas "biopolíticas da multidão" (HARDT e NEGRI, 2000, 2005 e 2009), portanto, seriam heterotopias capazes de transformar, em alguma medida, a vida urbana.

7. Ainda que não se concorde inteiramente com os argumentos proposto por Harvey (2009), sua perspectiva se revela interessante aos propósitos deste trabalho ao valorizar a ação transformadora dos atores sobre o território (sobre as relaçóes e dinâmicas de espaço-tempo).

8. A cultura tem sido acionada como "recurso" - muitas vezes performativo - capaz de atrair investimentos aos territórios (cf. YÚDICE, 2005).

9. Sobre este conceito, conferir também Beck, 2006.

10. Segundo Reis (2012, p. 80 e 81 ), diferentemente nas cidades criativas os processos são construídos de forma endógena e democrática, valorizando-se a cultura existente, isto é, as singularidades de cada território. Nessas cidades os objetivos são o de articular de forma mais harmoniosa possível os aspectos econômicos, ambientais, culturais e sociais, de modo que os beneficiários sejam efetivamente amplos setores da sociedade daquele território. De forma distinta a "lógica de (mega) projeto" que caracteriza as dinâmicas do city marketing, a cidade criativa é encarada como um processo contínuo que acaba até atraindo turistas e investidores, mas isso seria uma decorrência e não propriamente o objetivo final traçado.

11. Assiste-se desde 2014 no Brasil e especialmente no Estado do Rio de Janeiro a uma crise econômica que, em parte, está relacionada a queda do preço do barril do petróleo no mercado mundial.

12. Além disso, na última década, vem se destacando práticas espontâneas "engajadas", formas de "ativismo musical" que estrutura (ainda que provisoriamente) territorialidades "sônicas" ou "acústicas" (LABELLE, 2010) - não necessariamente organizadas por profissionais do mainstream ou do chamado setor independente da música - que vêm (re)potencializando a sociabilidade de territórios estratégicos do Centro do Rio de Janeiro, os quais correm o risco, ciclicamente, de "desvitalizarse”, como sugere a história dos últimos cem anos desta cidade (HERSCHMANN, 2007).

13. O que a municipalidade basicamente fez foi embelezar um pouco a localidade, regularizar o comércio de rua e as atividades culturais de rua, colocando as forças policiais para garantir a segurança pública neste bairro boêmio da cidade (HERSCHMANN, 2007).

14. Sobre a relevância dos gêneros musicais, cf. Negus, 2005.

15. Mais detalhes, conferir mapeamento dos municípios produzido pela FIRJAN: 
<http://www.firjan.com.br/EconomiaCriativa/pages/default.aspx>. Último acesso: 10.04 .2016$)$.

16. Parte significativa da pesquisa de campo realizada nesta cidade pode ser acessada no capítulo intitulado "Conservatória: ruas que cantam”, do livro Músicas nas ruas do Rio de Janeiro (HERSCHMANN e FERNANDES, 2014).

17. Vale ressaltar que as entrevistas e as observaçóes de campo deste estudo de caso ainda estão em um estágio inicial. Contudo, os atores (músicos e lideranças locais) em seus depoimentos salientam que, nos últimos anos começaram a surgir músicos e grupos locais que tocam jazz e blues, inclusive já tendo participado de algumas ediçōes deste festival (Oliveira, 2014).

18. Boa parte das reflexóes desenvolvidas aqui foram construídas a partir de entrevistas e as observaçóes de campo realizadas na área central da cidade do Rio de Janeiro. Para mais informaçóes a respeito desta investigação, conferir: HERSCHMANN e FERNANDES, 2014 e 2015.

19. Região da cidade do Rio compreendida pelos bairros da Gamboa e Saúde, no qual viveram grupos remanescentes dos quilombos da Pedra do Sal e Santo Cristo. Na ocasiáo da realização das obras, vários representantes de movimentos sociais denunciaram que as reformas Zona Portuária estavam destruindo sítios arqueológicos importantes.

20. As "políticas do comum" caminhariam para além do Estado de bem-estar social (do mundo institucionalizado), buscando potencializar formas de conduta e de subjetivação que deslizam dos mecanismos disciplinares e de controle (fabris ou pós-fabris e do biopoder do capital financeiro transnacional) em direção a uma dinâmica que privilegie a cooperaçáo dos atores (da Multidáo), o encontro de singularidades, a mobilização e constituição relativamente autônoma da vida social (HARDT e NEGRI, 2009).

21. Cf., entre outras obras, HERSCHMANN e FERNANDES, 2014; PRESTES FILHO et al., 2004.

22. Apesar de não ter sido muito enfatizado neste artigo, evidentemente os aspectos arquitetônicos e a "paisagem" das cidades pesquisadas (aspectos físicos, sociais, culturais, etc.) afetam a experiência urbana, a percepção dos atores sobre a ambiência dos territórios. Tanto o Centro do Rio quanto as cidades de Conservatória e Rio das Ostras são em geral identificados pelos atores como territórios que são aprazíveis e atraentes. Para mais detalhes sobre a relevância desses aspectos e sua contribuição para o dinamismo das localidades, ver FERNANDES, 2011.

23. No caso da cidade do Rio, vale destaque ainda para a Lei do Artista de Rua. Infelizmente esta pode ser abolida a qualquer momento, pois está tramitando na assembleia desta municipalidade um projeto para revogá-la. Lideranças dos setores mais conservadores da populaçáo argumentam que esta lei está criando uma séria perturbação sônica e, de modo geral, à ordem pública (Fernandes, Trotta e Herschmann, 2015). 